\title{
Early Detection of Mycoplasma hyopneumoniae in Pigs under Field Conditions Using Tracheo-bronchial Swab Sampling
}

\author{
Vangroenweghe $\mathrm{F}^{1,2 *}$ \\ ${ }^{1}$ Elanco Benelux, BU Food Animals, Plantijn en Moretuslei 1 - 3rd floor, 2018 Antwerpen, Belgium \\ ${ }^{2}$ Department Obstretics-Reproduction-Herd Health, Faculty of Veterinary Medicine, Unit of Porcine Health Management, Ghent University, Salisbury- \\ laan 133, 9820 Merelbeke, Belgium
}

*Corresponding author: Vangroenweghe F, Elanco Animal Health Benelux, Antwerp, Belgium; Email: vangroenweghe.frederic@telenet.be

Received: June 5, 2020; Accepted: June 15, 2020; Published: June 22, 2020

\begin{abstract}
Tracheo-bronchial swab (TBS) sampling is a rapid, reliable and animal-friendly diagnostic sampling of the respiratory tract for detection of Mycoplasma hyopneumoniae (M. hyopneumoniae). This mini-review gives an overview of different diagnostic approaches for M. hyopneumoniae from clinical signs, necropsy, microscopy to detection of the pathogen by immunohistochemistry, culture and PCR techniques. Subsequently, development, validation and obtained results are described using TBS for the early detection of $M$. hyopneumoniae in pigs with clinical symptoms of respiratory distress from 2 weeks of age onwards. Future perspectives on the application of TBS in diagnostic concepts, epidemiology and gilt adaptions protocols are also discussed.
\end{abstract}

Keywords: Mycoplasma hyopneumoniae, Swab sampling

\section{Introdcution}

\section{Diagnostic approach for Mycoplasma hyopneumoniae}

Diagnostic approach towards Mycoplasma hyopneumoniae (M. hyopneumoniae), a major pathogen in PRDC with a large economic impact on profitability of modern pig production, remains a difficult issue under practical conditions [1-3]. Throughout the years, a broad variety of diagnostic methods have been developed and evaluated for diagnosis of $M$. hyopneumoniae under field conditions. These diagnostic methods range from assessment of clinical signs of coughing and a coughing index [4-9], macroscopic and microscopic lesions at necropsy, including immunohistochemical [10,11] and immunofluorescent identification of $M$. hyopneumoniae in lung tissue samples [12,13]. Additionally, different lung scoring systems at slaughter have been developed [14]. Laboratory diagnostics include serology from complement fixation tests to ELISA based on several specific adhesion factors [15-17] and molecular identification of the pathogen in several sample types, such as lung tissue, nasal swabs (NS) [18-20], laryngeal swabs (LS), broncho-alveolar lavage fluid (BALF) [21,22] and tracheo-bronchial swabs (TBS) [22-24]. However, under field conditions and for standard monitoring purposes, swine veterinarians and routine diagnostic laboratories have limited their approach mostly to clinical signs, macroscopic and microscopic evaluation upon necropsy, including lung lesion scoring at slaughter and serological monitoring. Clinical signs and lung lesions can only give a tentative diagnosis, which needs further confirmation with laboratory tests. Recently, the use of mobile systems (SOMO; SoundTalks NV, Leuven, Belgium) for cough recording at barn level with subsequent analysis of coughing patterns have been developed and validated under field conditions [2]. This innovative tool might support early M. hyopneumoniae diagnosis, although it still remains difficult to specifically differentiate coughing by M. hyopneumoniae from other major pathogens involved in PRDC, such as IAV-S, PRRSV and A. pleuropneumoniae. Therefore, even with a positive indication on clinical $M$. hyopneumoniae-indicative coughing, confirmation through pathogen identification remains crucial for further implementation of treatment or preventive measures. The early detection of $M$. hyopneumoniae through necropsy or lung lesion scoring systems at slaughter also remains under discussion. The lesions, namely purple to grey consolidated areas affecting predominantly the apical and middle lobes and eventually the cranial part of the diaphragmatic lobes, identified in both necropsy or slaughterhouse assessment are suggestive, but not pathognomonic for M. hyopneumoniae infection [2]. Other pathogens such as IAV-S or $P$. multocida should be considered as most probable differential diagnoses [1]. Moreover, since animals are dead or slaughtered at the moment of the diagnosis, the definition of 'early' detection cannot really be applied and curative or preventive measures will only have an effect on the next batches of animals within the same production system. For several decades, therefore, serological tests - more specifically ELISA - have been used to detect and monitor M. hyopneumoniae at herd level. Early studies have shown a serious delay between the initial clinical signs of coughing and the first detection of M. hyopneumoniae using ELISA of about 22 days [25]. This delay in seroconversion has recently been reconfirmed for two commercially available ELISA tests, demonstrating a minimum interval of 21 days before the first 
incomplete seroconversion could be detected in both ELISA tests [3]. Moreover, substantial differences exist between different ELISA tests towards their reactivity following initial seroconversion $[3,17]$ in naive animals. Therefore, serological monitoring can neither be considered as a tool for early M. hyopneumoniae detection under field conditions. Nevertheless, for routine farm monitoring and follow-up on changes in M. hyopneumoniae infection pattern due to adaptations of management or vaccination strategy, serological tests have clearly shown their value [26].

\section{Tracheo-bronchial swab sampling - development and validation}

Taking these considerations into account, a reliable and early detection of $M$. hyopneumoniae in living animals under field conditions is urgently needed in order to be able to confirm an upcoming infection as early as possible. This is crucial under modern pig farming conditions to efficiently apply curative and preventive measures to omit further spread of the pathogen within the farm. Especially lactating gilts with an active M. hyopneumoniae infection present in the farrowing room imply a major risk for further transmission of M. hyopneumoniae to their offspring, resulting in a fairly high number of $M$. hyopneumoniae-positive piglets at weaning [18-20,23,27-31]. However, until recently, most M. hyopneumoniae prevalence studies in piglets and sows have been conducted using a rather easily applicable sampling technique, namely NS [18-20,2728,31]. More recently, others have applied BALF or lung tissue sampling to study $M$. hyopneumoniae prevalence around weaning age $[29,30]$ (Table 1).

Tracheo-bronchial swab (TBS) sampling technique has been developed as a diagnostic tool to screen pigs for respiratory pathogens, such as M. hyopneumoniae, through sampling of live pigs without anesthesia at the level of the trachea-bronchial split $[9,23]$. A study comparing different sampling techniques for M. hyopneumoniae recovery in piglets has demonstrated that NS have 3.89 times less sensitivity in recovering $M$. hyopneumoniae from infected piglets as compared to the TBS technique, with LS and BALF in an intermediate position (1.39 and 1.09 times less sensitivity compared to TBS, respectively) [23]. Moreover, the amount of DNA material recovered from TBS samples was higher as compared to other diagnostic techniques in live pigs [32-34]. Recent research into welfare aspects of respiratory tract sampling demonstrated no additional stress when sampling pigs by TBS as compared to NS [35].

\section{Tracheo-bronchial swab sampling - technical aspects}

In order to perform TBS sampling in a comfortable way, fixation of the piglet using a rope and positioning the head in a hyperextensive position is key for success. The hyperextension is important to gain easy access to the glottis to subsequently go down the trachea. A mouth opener is positioned and the catheter is passed through the mouth down to the pharyngeal region, where a slight resistance might be observed at the level of the glottis. When the piglet stops screaming, the glottis will open for inhalation and the catheter can be moved further down the trachea to the level of the trachea-bronchial split. There, the catheter tip is turned around to collect as much mucus as possible. After retraction of the catheter, the tip (max. $10 \mathrm{~cm}$ ) is collected in a sterile transport tube $(10 \mathrm{~mL})$ with $1 \mathrm{~mL}$ of sterile physiological saline $(0.9 \% \mathrm{NaCl})$ and transported to the analytic laboratory [33,36] (Figure 1).

A systematic quality check can be performed during the live sampling procedure to assess for correct sampling location [37].

\section{Tracheo-bronchial swab sampling - high detection through optimal DNA recovery}

To further elaborate on the TBS sampling, performance of TBS was compared to NS and bronchial swabs (BS), BALF and lung tissue samples in relation to detection of M. hyopneumoniae [33]. Recovery of M. hyopneumoniae was overall highest (59.3\%) in TBS, whereas other sampling techniques such as NS had a limited recovery rate (6.25\%). All three post-mortem sampling techniques - BALF, lung tissue samples and BS - had a good recovery (46.7 to $51.0 \%$ ), though as already stated earlier, for monitoring purposes, sampling techniques in live animals should be preferred. Although BALF can also be performed

Table 1: Studies of M. hyopneumoniae prevalence at various ages (expressed as \% M. hyopneumoniae-positive piglets) using different sampling techniques.

\begin{tabular}{|c|c|c|c|}
\hline Piglet age (weeks) & $\begin{array}{c}\text { Prevalence (\%) } \\
\text { M. hyopneumoniae }\end{array}$ & Sampling technique & References \\
\hline 3 & $7.7-9.6$ & NS & Calsamiglia and Pijoan, 2000 [18] \\
\hline 3 & $2.6-13.2$ & NS & Ruiz et al., 2003 [27] \\
\hline $1-3$ & $0.5-5.5$ & NS & Sibila et al., 2007 [19] \\
\hline $6-9$ & $2.0-9.0$ & NS & Sibila et al., 2007 [28] \\
\hline 3 & $0.0-51.3$ & NS & Fano et al., 2007 [29] \\
\hline 3 & 10.6 & BALF & Moorkamp et al., 2009 [29] \\
\hline 6 & 12.3 & BALF & Moorkamp et al., 2009 [29] \\
\hline 2 & 2.0 & Lung & Nathues et al., 2010 [30] \\
\hline $4-10$ & 9.3 & Lung & Nathues et al., 2010 [30] \\
\hline 3 & 10.7 & NS & Villarreal et al., 2010 [31] \\
\hline 4 & 14.1 & TBS & Fablet et al., 2012 [24] \\
\hline $2.5-3$ & 3.9 & NS & Nathues et al., 2013 [20] \\
\hline 2 & 1.1 & TBS & Vangroenweghe et al., 2015a [33] \\
\hline $3-5$ & 7.1 & TBS & Vangroenweghe et al., 2015b [36] \\
\hline $6-11$ & 10.9 & TBS & Vangroenweghe et al., 2015b [36] \\
\hline \multicolumn{4}{|c|}{ NS, nasal swab; BALF, broncho-alveolar lavage fluid; TBS, tracheo-bronchial swab. } \\
\hline
\end{tabular}




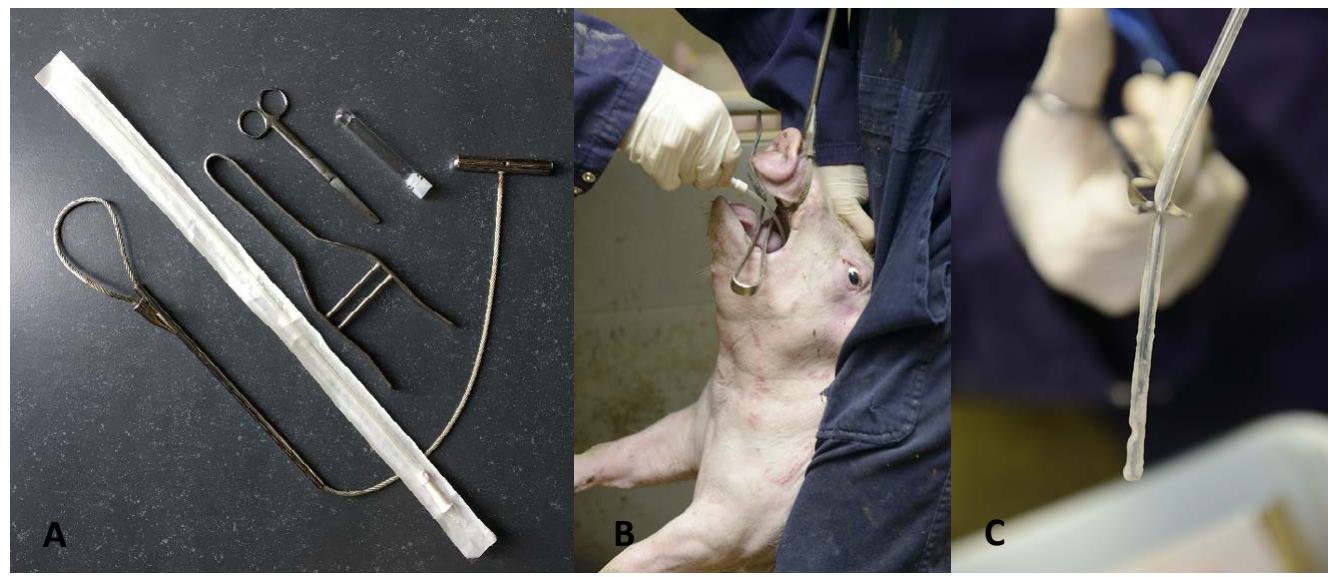

Figure 1: A. Set of materials needed for TBS sampling (from left under to right up), including nasal rope, sample catheter, mouth opener, scissors and a $10 \mathrm{~mL}$ transportation tube containing $1 \mathrm{~mL}$ of sterile physiological saline $(0.9 \% \mathrm{NaCl})$ solution; B. Optimal piglet fixation and presentation to obtain a TBS sample; $\mathbf{C}$. Sample catheter with mucus on the tip ready to cut in the transportation tube.

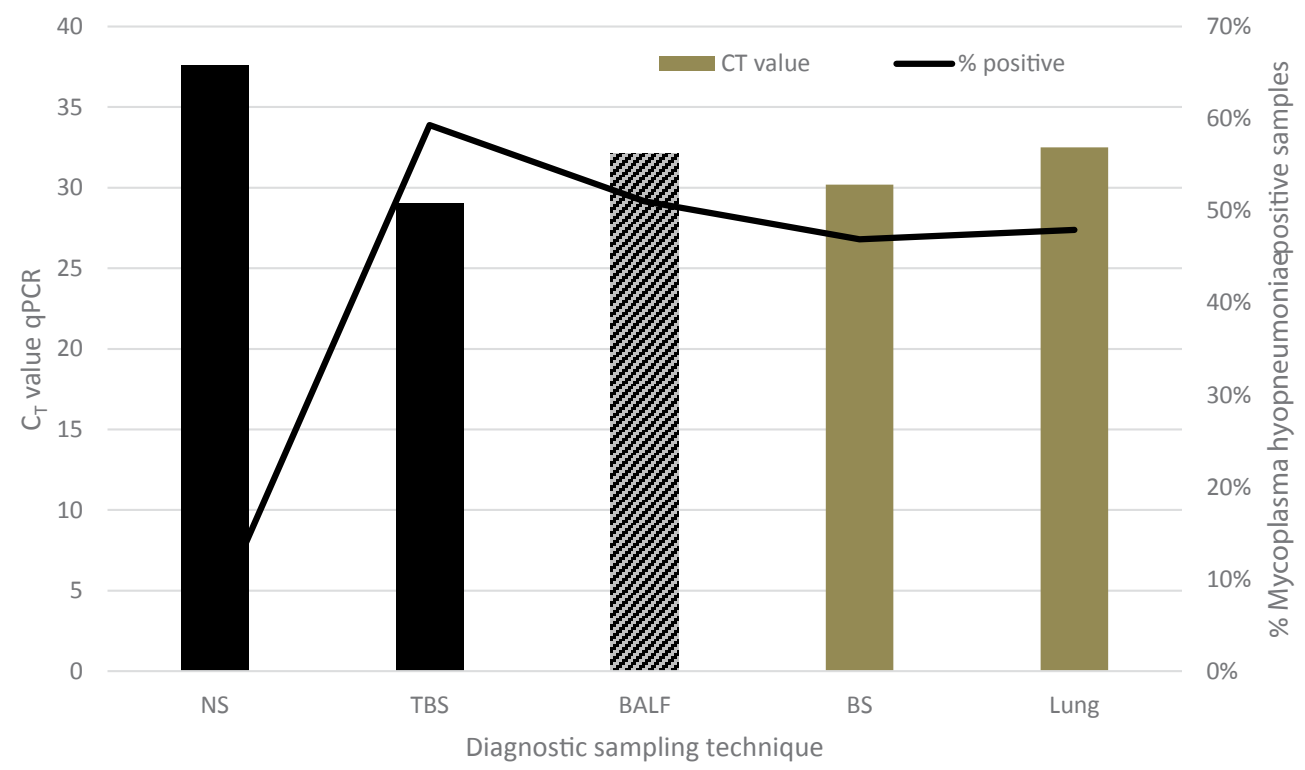

Figure 2: Comparison among different diagnostic sampling techniques combined with qPCR detection for M. hyopneumoniae in relation to estimated amount of DNA material (expressed as $\mathrm{C}_{\mathrm{T}}$ value) and percentage of positively detected animals. Black bars indicate live sampling techniques grey bars indicate sampling techniques in dead animals. NS - nasal swab; TBS - tracheabronchial swab; BALF - broncho-alveolar lavage fluid; BS - bronchial swab; Lung - lung tissue sample (adapted from Vangroenweghe et al., 2015a).

in live animals, to our opinion, BALF sampling technique has several disadvantages for live piglet sampling as compared to TBS. There is need to sedate animals before the procedure and a more rigid catheter is needed for the intervention, which might harm the tubular structure of trachea or larger bronchi. A major concern is the variability in recovered fluid volume from the lavage in different piglets, which might interfere with the detection limit of the M. hyopneumoniae qPCR used in these samples. Evaluation of the level of recovery of M. hyopneumoniae (based on the $\mathrm{C}_{\mathrm{T}}$ values in the $\mathrm{qPCR}$ ) for the live piglet sampling techniques, TBS samples resulted in the lowest $C_{T}$ values, whereas NS had a significantly lower yield in the qPCR. Only BS samples revealed a comparable recovery to TBS with lung tissue samples and BALF obtaining intermediate results (Figure 2).

However, these samples - except for BALF - can only be taken in dead animals and are therefore not suitable for the intended purpose of live monitoring to detect M. hyopneumoniae at an early stage.
Another field study on fattening pigs with clinical signs typical for $M$. hyopneumoniae compared three sampling techniques - TBS, LS and the pharyngeal spoon technique - for their detection of M. hyopneumoniae $[32,34]$. Whereas the LS collects mucus at the level of the larynx, using a speculum and a long dry cotton swab, the pharyngeal spoon technique collects mucus just cranial to the laryngeal region, using an elongated spoon. In this study, fattening pigs sampled with all three techniques were positive for M. hyopneumoniae. However, TBS consistently had the lowest $C_{T}$ value, indicating the highest amount of collected genetic material (DNA) from the pathogens present at the level of the respiratory tract (Figure 3).

\section{Tracheo-bronchial swab sampling and early detection of $M$.} hyopneumoniae

Early detection of M. hyopneumoniae infection is essential in case of SPF breeding herds. In two recent case reports, TBS-qPCR 


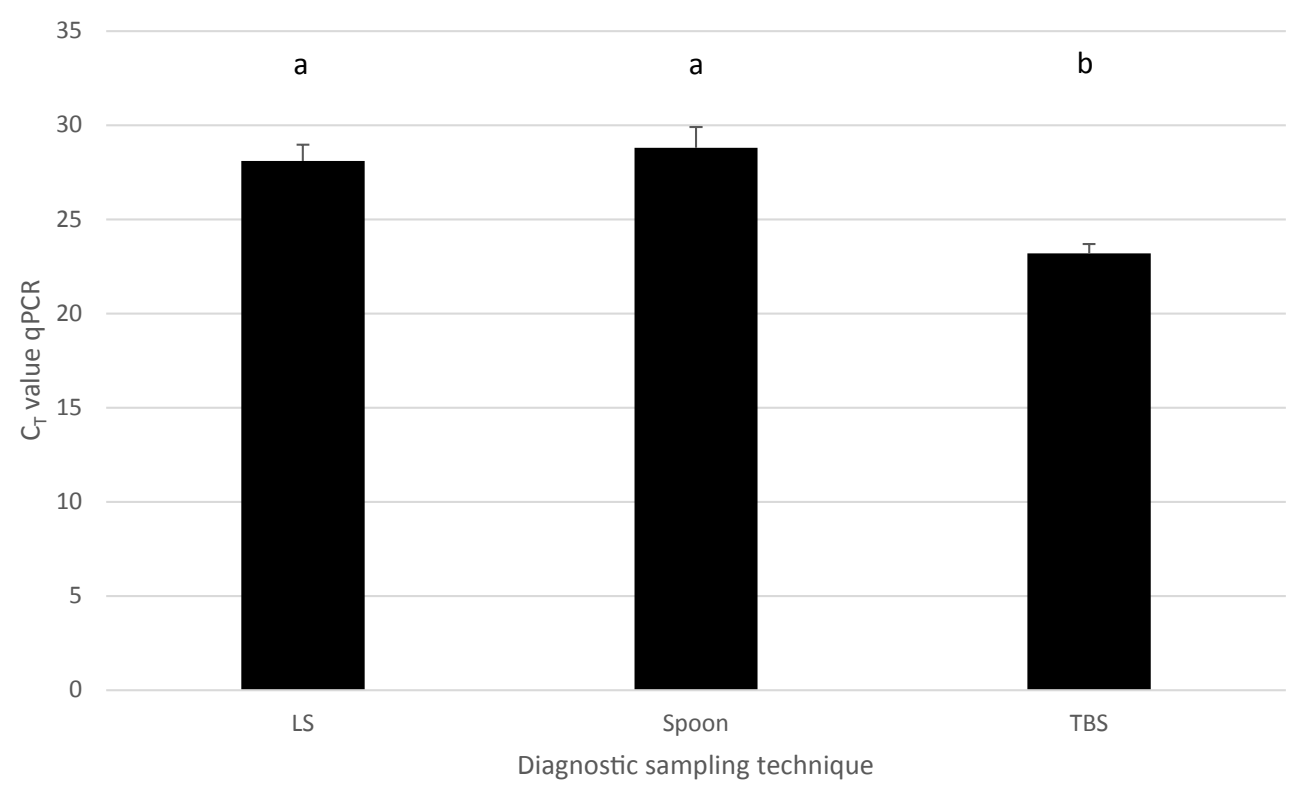

Figure 3: Comparison among different diagnostic sampling techniques combined with qPCR detection for $M$. hyopneumoniae in relation to estimated amount of DNA material (expressed as $\mathrm{C}_{\mathrm{T}}$ value \pm SEM). Different letters in superscript indicate significant differences $(P=0.046)$. LS - laryngeal swab; Spoon - deep pharyngeal spoon technique; TBS - tracheo-bronchial swab $($ adapted from Betlach et al., 2018 and Vangroenweghe et al., 2018).

has been demonstrated to detect M. hyopneumoniae at the moment where serology and lung lesions scoring still remained negative. Therefore, TBS should be the preferred option to screen a farm for $M$. hyopneumoniae-free certification and to capture early introduction of M. hyopneumoniae [38,39].

\section{Tracheo-bronchial swabs sampling: future perspectives and applications}

1. Mycoplasma hyopneumoniae diagnosis should be further elaborated, especially towards the optimization of sampling protocols for specific field conditions, such as early detection of the pathogen, certification of freedom of disease or other diagnostic approaches. Nowadays, it becomes more and more important to have a rapid and reliable diagnosis and therefore PCR tests should be available wherever possible and needed. Recent evolutions towards on-farm test applications (LAMP and helicase-dependent amplification technology [40] and on-site PCR kits) should be further developed and validated in order to have immediate results. This would help to determine an efficient treatment, which could result in less antibiotic use as compared to treatment of animals already suffering from M. hyopneumoniae in a more chronic stage of the disease.

2. In the near future, technology already applied in clinical and food microbiology will become readily available for use in veterinary diagnostic laboratories. Besides automation in the form of sample-to-result instrumentation for qPCR assay, which reduces labor and limits the risk for contamination during manipulation, multiplex tests are now available that enable single specimens to be evaluated for the presence of multiple pathogens associated with various clinical syndromes. Digital PCR and next-generation sequencing will push the landscape of molecular diagnostics further, allowing for analysis of complex, polymicrobial specimens and enabling accurate quantification of organisms present at very low levels $(<0.01 \%$ of the microbial consortium) in a specimen [40]. Another promising technique is Matrix-Assisted Laser Desorption Ionization-Time to Flight MS (MALDI-TOF), which enables the identification of bacteria and other microorganisms by non-fragmenting or 'soft ionization' techniques [40]. If these technologies become available for M. hyopneumoniae diagnostics, faster and more accurate diagnosis can be performed, especially if combined with a sampling technique that provides a high yield of pathogenic material, such as TBS.

3. TBS combined with improved isolation methods - such as automation of primary processing and plating, coupled with initial culture examination aided by high-resolution optics [40] - could help to improve collection of field strains to further monitor antimicrobial sensitivity (MycoPath; [41]) which in turn would assist in reducing ineffective treatments against M. hyopneumoniae in case of antimicrobial resistance.

4. Mycoplasma hyopneumoniae epidemiology remains a challenging domain of research, which still undergoes interesting new evolutions, especially within the field of early gilt exposure to $M$. hyopneumoniae in order to prevent excretion during lactation which might affect her piglets' $M$. hyopneumoniae infection status. Recently, several studies have been performed to evaluate the optimal transmission of $M$. hyopneumoniae from infected to naive gilts through direct contact $[42,43]$ or using more challenging techniques such as intra-tracheal inoculation [43] or even aerosol applications of lung homogenate $[43,44]$. In these cases, M. hyopneumoniae transmission success is crucial for future stability of on-farm M. hyopneumoniae infection status (Figure 4). 


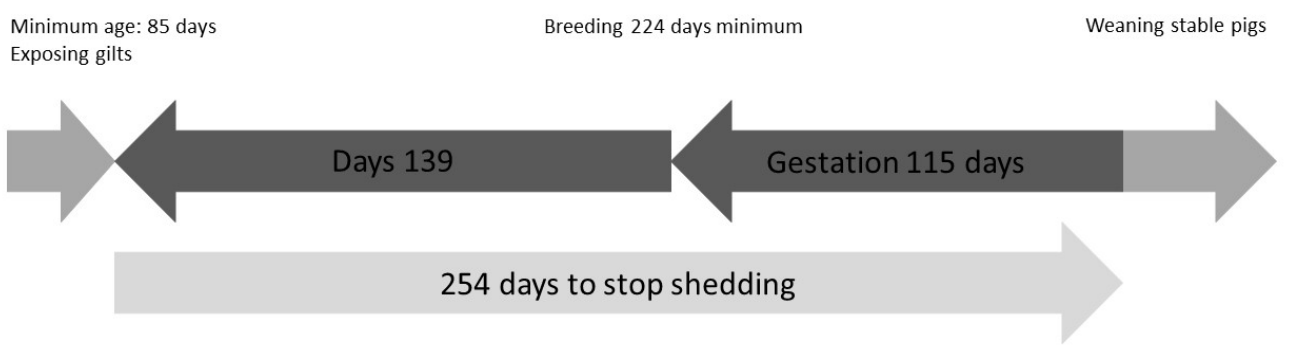

Figure 4: Gilt M. hyopneumoniae exposure timeline based on the 254 days of M. hyopneumoniae detection from initial infection onwards [45] (adapted from [43]).

Table 2: Overview of M. hyopneumoniae diagnostic sampling options for specific practical situations, combined with the average interval (expressed in days) between infection moment and first possible detection moment, the positivity at first detection (expressed as \% M. hyopneumoniae-positive samples) and estimated amount of DNA material collected with each specific diagnostic sampling option. Interval infection $v$ s. positivity was based on Pieters et al., 2017.

\begin{tabular}{|c|c|c|c|c|c|}
\hline $\begin{array}{l}\text { Diagnostic sampling option } \\
\text { and detection technique }\end{array}$ & $\begin{array}{l}\text { Status } M . \text { hyopneumoniae } \\
\text { end of fattening period }\end{array}$ & $\begin{array}{l}\text { Early M. hyopneumoniae } \\
\text { infection }\end{array}$ & $\begin{array}{l}\text { Acute outbreak of } M . \\
\text { hyopneumoniae }\end{array}$ & $\begin{array}{c}\text { Interval infection - positivity } \\
\text { (days/\% positive) M. hyopneumoniae }\end{array}$ & $\begin{array}{c}\text { Estimated amount of DNA } \\
\text { material collected }\end{array}$ \\
\hline Nasal swab - PCR & - & \pm & \pm & $5 \mathrm{~d}(14 \%)$ & + \\
\hline BALF - PCR & + & ++ & ++ & $5 \mathrm{~d}(19 \%)$ & ++ \\
\hline TBS - PCR & ++ & +++ & +++ & $5 \mathrm{~d}(80 \%)$ & +++ \\
\hline Oral fluids - PCR & + & - & - & $9-28 d(67 \%)^{*}$ & + \\
\hline Serology - ELISA & ++ & - & - & $21 \mathrm{~d}(12 \%)$ & N/A \\
\hline Lung lesions scoring & ++ & - & - & N/A & N/A \\
\hline
\end{tabular}

5. Under these conditions, TBS could be applied to check for inoculation success in the earliest possible way. Interestingly, the above stated inoculation methods are still under development and evaluation concerning the inoculum dose, the number of subsequent exposure events and the efficacy to transmit M. hyopneumoniae to all animals exposed [45,46]. Currently, no standard protocol is available and therefore, additional research should be carried out to determine the minimal exposure in order to obtain colonization of the respiratory tract. For these purposes, TBS could be applied as an early detection tool to assess inoculation success.

6. Besides the deliberate or accidental exposure of gilts to $M$. hyopneumoniae, checking the actual $M$. hyopneumoniae status in farms is also of major importance. A recent survey on M. hyopneumoniae gilt introduction in conventional farms revealed major room for improvement, especially towards increasing the knowledge on the M. hyopneumoniae status of replacement gilts at the moment of arrival into the quarantine/ adaptation facilities [47]. Again, early M. hyopneumoniae detection is crucial in order to adapt the preventive measures to the current health status at gilt delivery. In case of $M$. hyopneumoniae-positive gilts, curative treatment might be considered, whereas in case of a M. hyopneumoniae-negative status, correct vaccination with a M. hyopneumoniae vaccine might be considered to rapidly boost the gilt's immunity before exposure at introduction into the existing conventional M. hyopneumoniae-positive sow population [48].

7. Finally, as piglet infection status for M. hyopneumoniae at weaning is a leading indicator towards the percentage of lung lesions at slaughter [28], it still remains of major importance to monitor the M. hyopneumoniae infection status of piglets on a regular basis. Especially since it has been clearly demonstrated that between-batch variability might be high and unpredictable based on the previous batch [28]. Within these monitoring schedules focused on early detection of M. hyopneumoniae, TBS could play a predominant role in the near future. Knowledge on the 'information' gap between M. hyopneumoniae detection using serology and TBS is also key in case of SPF certification programs for breeding herds producing M. hyopneumoniaefree gilts, in order to guarantee continuous delivery of $M$. hyopneumoniae-free reproduction gilts to end-customers or for their internal replacement [36-37].

\section{Conclusion}

Early diagnosis of $M$. hyopneumoniae in young piglets and at first clinical symptoms can be easily performed using TBS sampling. A comprehensive overview of the different diagnostic options and their potential for early diagnosis are given in Table 2 . Different diagnostic scenarios are given: $M$. hyopneumoniae status at the end of the fattening period, detection of early M. hyopneumoniae infection in piglets and in case of acute respiratory disease. Tracheo-bronchial swab sampling has the potential to both detect $M$. hyopneumoniae at an early stage in life and during infection, especially due to the collection of a sufficient high amount of pathogen material from the respiratory tract during sampling. This confirms TBS combined with qPCR as the preferred method for M. hyopneumoniae diagnostics.

\section{References}

1. Sibila M, Pieters M, Molitor T, Maes D, Haesebrouck F, et al. (2009) Current perspectives on the diagnosis and epidemiology of Mycoplasma hyopneumoniae infection. Veterinary Journal 181: 221-231. [crossref]

2. Maes D, Sibila M, Kuhnert P, Segalés J, Haesebrouck F, et al. (2017) Update on Mycoplasma hyopneumoniae infections in pigs: knowledge gaps for improved disease control. Transboundary and Emerging Diseases 62: 1-15. [crossref] 
3. Pieters M, Daniels J, Rovira D (2017) Comparison of sample types and diagnostic methods for in vivo detection of Mycoplasma hyopneumoniae during early stages of infection. Veterinary Microbiology 203: 103-109. [crossref]

4. Morris CR, Gardner IA, Hietala SK, Carpenter TE, Anderson RJ, et al. (1995) Seroepidemiologic study of natural transmission of Mycoplasma hyopneumoniae in a swine herd. Preventive Veterinary Medicine 21: 323-337.

5. Maes D, Deluyker H, Verdonck M, Castryck F, Miry C, et al. (1999) Risk indicators for the seroprevalence of Mycoplasma hyopneumoniae, porcine influenza viruses and Aujeszky's disease virus in slaughter pigs from fattening pig herds. Journal of Veterinary Medicine 46: 341-352. [crossref]

6. Thacker EL, Thacker BJ, Young TF, Halbur PG (2000) Effect of vaccination on the potentiation of porcine reproductive and respiratory syndrome virus (PRRSV)induced pneumonia by Mycoplasma hyopneumoniae. Vaccine 18: 1244-1252. [crossref]

7. Vicca J, Stakenborg T, Maes D, Butaye P, Peeters J, de Kruif A, Haesebrouck F (2003) Evaluation of virulence of Mycoplasma hyopneumoniae field isolates. Veterinary Microbiology 97: 177-190. [crossref]

8. Meyns T, Dewulf J, de Kruif A, Calus D, Haesebrouck F, et al. (2006) Comparison of transmission of Mycoplasma hyopneumoniae in vaccinated and non-vaccinated populations. Vaccine 24: 7081-7086. [crossref]

9. Marois C, Le Carrou J, Kobisch M, Gautier-Bouchardon AV (2007) Isolation of Mycoplasma hyopneumoniae from different sampling sites in experimentally infected and contact SPF pigs. Veterinary Microbiology 120: 96-104. [crossref]

10. Sarradell J, Andrada M, Ramírez AS, Fernández A, Gómez-Villamandos JC, et al. (2003) A morphologic and immunohistochemical study of the bronchus-associated lymphoid tissue of pigs naturally infected with Mycoplasma hyopneumoniae. Veterinary Pathology 40: 395-404. [crossref]

11. Rodriguez F, Ramirez GA, Sarradell J, Andrada M, Lorenzo H (2004) Immunohistochemical labeling of cytokines in lung lesions of pigs naturally infected with Mycoplasma hyopneumoniae. Journal of Comparative Pathology 130: 306-312. [crossref]

12. Kobisch M, Tillon J, Vannier P, Magneur S, Morvan P (1978) Pneumonie enzootique à Mycoplasma suipneumoniae chez le porc: diagnostic rapide et recherches d'anticorps. Recueil de Médecine Vétérinaire 154: 847-852.

13. Piffer I, Ross RF (1985) Immunofluorescence technique for detection of Mycoplasma hyopneumoniae in swine lungs. Pesquisa Agropecuáia Brasileira 20: 877-882.

14. Garcia-Morante B, Segalés J, Fraile L, Pérez de Rozas A, Maiti H, et al. (2016) Assessment of Mycoplasma hyopneumoniae-induced pneumonia using different lung lesions scoring systems: a comparative review. Journal of Comparative Pathology 154: 125-134. [crossref]

15. Strait EL, Erickson BZ, Thacker EL (2004) Analysis of Mycoplasma hyopneumoniae field isolates. In: Proceedings of $35^{\text {th }}$ Annual Meeting of American Association of Swine Veterinarians. Des Moines, IA. p. 95

16. Ameri-Mahabadi M, Zhou E-M, Hsu WH (2005) Comparison of two swine Mycoplasma hyopneumoniae enzyme-linked immunosorbent assays for detection of antibodies from vaccinated pigs and field serum samples. Journal of Veterinary Diagnostic Investigation 17: 61-64. [crossref]

17. Erlandson KR, Evans RB, Thacker BJ, Wegner MW, Thacker EL (2005) Evaluation of three serum antibody enzyme-linked immunosorbent assays for Mycoplasma hyopneumoniae. Journal of Swine Health and Production 13: 198-203.

18. Calsamiglia M, Pijoan C (2000) Colonisation state and colostral immunity to Mycoplasma hyopneumoniae of different parity sows. Veterinary Record 146: 530532. [crossref]

19. Sibila M, Nofrarias M, Lopez-Soria S, Segalés J, Riera P, Llopart D, Calsamiglia M (2007) Exploratory field study on Mycoplasma hyopneumoniae infection in suckling pigs. Veterinary Microbiology 121: 352-356. [crossref]

20. Nathues H, Woeste H, Doehring S, Fahrion AS, Doherr MG, et al. (2013) Herd specific risk factors for Mycoplasma hyopneumoniae infections in suckling pigs at the age of weaning. Acta Veterinaria Scandinavica 55: 30-42. [crossref]

21. Kurth KT, Hsu T, Snook ER, Thacker EL, Thacker BJ, et al. (2002) Use of a Mycoplasma hyopneumoniae nested polymerase chain reaction test to determine the optimal sampling sites in swine. Journal of Veterinary Diagnostic Investigation 14: 463-469. [crossref]
22. Marois C, Cariolet R, Morvan H, Kobisch M (2008) Transmission of pathogenic respiratory bacteria to specific pathogen free pigs at slaughter. Veterinary Microbiology 129: 325-332. [crossref]

23. Fablet C, Marois C, Kobisch M, Madec F, Rose N (2010) Estimation of the sensitivity of four sampling methods for Mycoplasma hyopneumoniae detection in live pigs using a Bayesian approach. Veterinary Microbiology 143: 238-245. [crossref]

24. Fablet C, Marois C, Dorenlor V, Eono F, Eveno E, et al. (2012) Bacterial pathogens associated with lung lesions in slaughter pigs from 125 herds. Research in Veterinary Science 93: 627-630.

25. Sørensen V, Ahrens P, Barfod K, Feenstra AA, Feld NC, et al. (1997) Mycoplasma hyopneumoniae infection in pigs: duration of the disease and evaluation of four diagnostic assays. Veterinary Microbiology 54: 23-34. [crossref]

26. Vangroenweghe F, Suls L, Van Driessche E, Maes D, De Graef E (2012) Health advantages of transition to batch management system in farrow-to-finish pig herds. Veterinarni Medicina 57: 83-91.

27. Ruiz AR, Utrera V, Pijoan C (2003) Effect of Mycoplasma hyopneumoniae sow vaccination on piglet colonization at weaning. Journal of Swine Health and Production 11: $131-135$.

28. Fano E, Pijoan C, Dee S, Deen J (2007) Effect of Mycoplasma hyopneumoniae colonization at weaning on disease severity in growing pigs. Canadian Journal of Veterinary Research 71: 195-200. [crossref]

29. Moorkamp L, Hewicker-Trautwein M, große Beilage E (2009) Occurrence of Mycoplasma hyopneumoniae in coughing piglets (3-6 weeks of age) from 50 herds with a history of endemic respiratory disease. Transboundary and Emerging Disease 56: 54-56. [crossref]

30. Nathues H, Kubiak R, Tegeler R, große Beilage E (2010) Occurrence of Mycoplasma hyopneumoniae infections in suckling and nursery pigs in a region of high pig density. Veterinary Record 166: 194-198. [crossref]

31. Villarreal I, Vranckx K, Duchateau L, Pasmans F, Haesebrouck F, et al. (2010) Early Mycoplasma hyopneumoniae infections in European suckling pigs in herds with respiratory problems: Detection rate and risk factors. Veterinarni Medicina 55: 318-324.

32. Betlach A, Vangroenweghe F, Holst S, Evelsizer R, Pieters M (2018) Evaluating Mycoplasma hyopneumoniae by PCR using various sample types. In: Proceedings of Allan D. Leman Conference. Mineapolis, MN.

33. Vangroenweghe F, Karriker L, Main R, Christianson E, Marsteller T, et al. (2015) Assessment of litter prevalence of Mycoplasma hyopneumoniae in preweaned piglets utilizing an antemorten tracheobronchial mucus collection technique and real-time polymerase chain reaction assay. Journal of Veterinary Diagnostic Investigation 27: 606-610. [crossref]

34. Vangroenweghe F, Holst S, Willems E, Betlach A, Malasek J, et al. (2018) Tracheobronchial swab sampling as an early diagnostic tool to confirm Mycoplasma hyopneumoniae in a central European SPF breeding herd. In: Proceedings of $5^{\text {th }}$ Conference of European Association of Veterinary Laboratory Diagnosticians. Brussels, Belgium.

35. Wei $\beta$ C, Beffort L, Renken C, Froelich S, Zoels S, et al. (2018) Effect of tracheobronchial-swabbing and other diagnostic tools on the endocrine stress response of pigs. In: Proceeding of 9 European Symposium on Porcine Health Management. Barcelona, Spain. p. 86

36. Vangroenweghe F, Labarque G, Piepers S, Strutzberg-Minder K, Maes D (2015) Mycoplasma hyopneumoniae infections in peri-weaned and post-weaned pigs in Belgium and The Netherlands: prevalence and associations with climatic conditions. Veterinary Journal 205: 93-97. [crossref]

37. Vangroenweghe F (2018) Early detection of Mycoplasma hyopneumoniae in pigs under field conditions. PhD thesis - Faculty of Bioscience Engineering, Ghent University, Ghent, Belgium.

38. Vangroenweghe F, Willems E, Malášek J, Thas O, Maes D (2018) Use of tracheabronchial swab qPCR test to confirm Mycoplasma hyopneumoniae seropositivity in an SPF breeding herd. Porcine Health Management 4: 12-17.

39. Vangroenweghe F, Willems E, Thas O, Maes D (2018) Confirmation of Mycoplasma hyopneumoniae in a breeding herd through tracheobronchial swab sampling and PCR. Veterinary Record 183.

40. Buchan BW, Ledeboer NA (2018) Emerging Technologies for the Clinical Microbiology Laboratory. Clinical Microbiology Reviews 27: 783-822. [crossref] 
41. Klein U, de Jong A, Moyaert H, El Garch F, Leon R, (2017) Antimicrobial susceptibility monitoring of Mycoplasma hyopneumoniae and Mycoplasma bovis isolated in Europe. Veterinary Microbiology 204: 188-193. [crossref]

42. Roos LR, Fano E, Homwong N, Payne B, Pieters M (2016) A model to investigate the optimal seeder-to-naive ratio for successful natural Mycoplasma hyopneumoniae gilt exposure prior to entering the breeding herd. Veterinary Microbiology 184: 51-58. [crossref]

43. Yeske P (2018) Mycoplasma hyopneumoniae: lateral transmission and gilt exposure methods. In: Proceedings of $49^{\text {th }}$ Annual Meeting of American Association of Swine Veterinarians. San Diego, CA. p. 482-484.

44. Nickel M, Toohill E, Lehman J (2018) Use of a hurricane fogger for Mycoplasma hyopneumoniae inoculation in nursery age gilts. In: Proceedings of $49^{\text {th }}$ Annual Meeting of American Association of Swine Veterinarians. San Diego, CA. p. 97-98.
45. Pieters M, Pijoan C, Fano E, Dee S (2009) An assessment of the duration of Mycoplasma hyopneumoniae infection in an experimentally infected population of pigs. Veterinary Microbiology 134: 261-266. [crossref]

46. McMahon M, Garcia Morante B, Betlach A, De Abreu C, Robbins R, et al. (2020) Lung homogenate optimization for successful Mycoplasma hyopneumoniae exposure in gilts during acclimation. In: Proceedings of $51^{\text {st }}$ Annual Meeting of American Association of Swine Veterinarians. Atlanta, US. p. 73.

47. Garza-Moreno L, Segalés J, Pieters M, Romagosa A, Sibila M (2017) Survey on Mycoplasma hyopneumoniae gilt acclimatization practices in Europe. Porcine Health Management 3: 21-28.

48. Garza-Moreno L, Segalés J, Pieters M, Romagosa A, Sibila M (2018) Acclimation strategies in gilts to control Mycoplasma hyopneumoniae infection. Veterinary Microbiology 219: 23-29.

\section{Citation:}

Vangroenweghe F (2020) Early Detection of Mycoplasma hyopneumoniae in Pigs under Field Conditions Using Tracheo-bronchial Swab Sampling. Integr J Vet Biosci Volume 4(1): 1-7. 